\title{
Tension Structures
}


Downloaded by [] on [26/04/23]. Copyright (C ICE Publishing, all rights reserved. 


\section{Tension Structures}

Form and behaviour

\section{Second edition}


Published by ICE Publishing, One Great George Street, Westminster, London SW1P 3AA.

Full details of ICE Publishing representatives and distributors can be found at: www.icebookshop.com/bookshop_contact.asp

\section{Other titles by ICE Publishing:}

Shell Structures in Civil and Mechanical Engineering, Second edition.

A. Zingoni. ISBN 978-0-7277-6028-9

Conceptual Structural Design, Second edition.

A. Popovic. ISBN 978-0-7277-6110-1

www.icebookshop.com

A catalogue record for this book is available from the British Library

ISBN 978-0-7277-6173-6

(c) Wanda J Lewis 2018

ICE Publishing is a division of Thomas Telford Ltd, a wholly-owned subsidiary of the Institution of Civil Engineers (ICE).

All rights, including translation, reserved. Except as permitted by the Copyright, Designs and Patents Act 1988, no part of this publication may be reproduced, stored in a retrieval system or transmitted in any form or by any means, electronic, mechanical, photocopying or otherwise, without the prior written permission of the Publisher, ICE Publishing, One Great George Street, Westminster, London SW1P 3AA.

This book is published on the understanding that the author is solely responsible for the statements made and opinions expressed in it and that its publication does not necessarily imply that such statements and/or opinions are or reflect the views or opinions of the publishers. While every effort has been made to ensure that the statements made and the opinions expressed in this publication provide a safe and accurate guide, no liability or responsibility can be accepted in this respect by the author or publishers.

While every reasonable effort has been undertaken by the author and the publisher to acknowledge copyright on material reproduced, if there has been an oversight please contact the publisher and we will endeavour to correct this upon a reprint.

Cover image: Piazza Umbrellas in Madinah, Saudi Arabia

Commissioning Editor: Laura Balchin Development Editor: Maria Inês Pinheiro Production Editor: Madhubanti Bhattacharyya Market Development Executive: Elizabeth Hobson

Typeset by Manila Typesetting Company Index created by Simon Yapp and Wanda J Lewis Printed and bound in Great Britain by TJ International Ltd, Padstow 


\section{Contents}

Preface

Acknowledgements

About the author

01

1.1. Definitions and classifications

1.2. Strength and stiffness of architectural fabrics 3

1.3. Types of architectural fabrics 4

1.4. Boundary tensioned membranes 4

1.5. Pneumatic structures 10

1.6. Pre-stressed cable nets and beams 12

1.7. Design process of tension membranes 16

1.8. Main features of tension membranes 18

1.9. Conventional roofing forms versus tension membranes

1.10. Closing remarks 20

References $\quad 21$

$02 \ldots \ldots \ldots \ldots \ldots \ldots \ldots \ldots \ldots$ Form-finding 23

2.1. General concepts. Nature's 'secrets' 23

2.2. Concept of a 'minimal surface': historical background 26

2.3. Form-finding methodologies 28

References 35

$03 \ldots \ldots \ldots \ldots \ldots \ldots \ldots \ldots \ldots$ Geometrically nonlinear behaviour: solutions using commonly used numerical methods $\quad 37$

3.1. Geometric nonlinearity 37

3.2. Commonly used computational methods for the analysis of geometrically nonlinear behaviour

3.3. Transient stiffness method 39

3.4. Force density method (original formulation) 48

3.5. Dynamic relaxation method 54

3.6. Computational static analysis versus form-finding 54

References $\quad 55$

$04 \ldots \ldots \ldots \ldots \ldots \ldots \ldots \ldots \ldots$ Dynamic relaxation method 57

4.1. Dynamic relaxation method with viscous
damping

4.2. Dynamic relaxation method with kinetic damping 63

4.3. Application of dynamic relaxation to cable networks 67

4.4. Evaluation of the dynamic relaxation method 73 References 
05

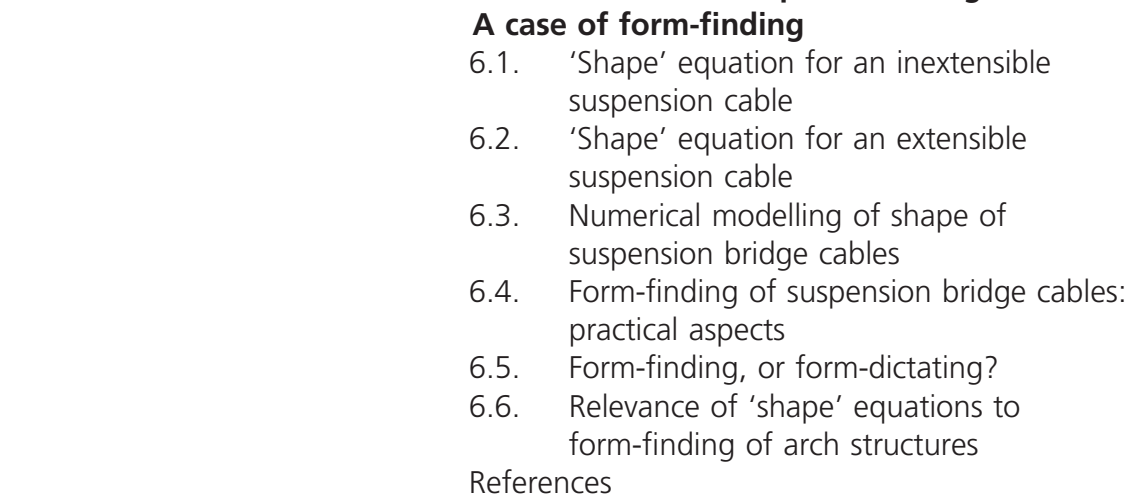

07

\section{Modelling of tension membranes}

7.1. Introduction

7.2. Surface discretisation

7.3. Surface discretisation for use with the transient stiffness method: limitations of the approach

7.4. Surface discretisations used with the dynamic relaxation method

7.5. Line elements in modelling of stable minimal surface membranes

7.6. Application of triangular elements to modelling of stable minimal surface membranes

7.7. Mesh control - implications for design 156

7.8. Patterning of membranes

7.9. Numerical accuracy and criteria used for convergence

7.10. Data processing

References

Architectural fabrics

Appendix I

Cables for tension structures

Appendix III

Minimal surfaces

185

Appendix IV

Viscous damping in dynamic relaxation

Appendix V

Finite-difference analysis of inextensible cable. Load case 1: deck weight only

Index 
Tension structures discussed in this research monograph cover pre-stressed cable nets, girders, trusses, and fabric membranes. Attention is also drawn to cables in suspension bridges - a special form of a cable truss.

In their tensioned state, cables and fabrics adopt unique geometric configurations, which cannot be described by simple mathematical functions. Instead, they have to be found through iterative computations supported by physical experiments - a process known as 'form-finding'. Formfinding is a theme running through almost all chapters of the book, highlighting conceptual design issues and advocating the use of principles observed in nature when seeking to achieve optimal structural forms, or 'minimal' structures. The form-finding methodology is extended to suspension bridge cables, to emphasise the fact that they are not structures of 'known shape'.

The second edition covers the most commonly used computational methods used in modelling tension structures, but also contains a significant amount of new material, which includes:

- wide coverage of tension structures projects, focusing on iconic designs around the world

- a more detailed description of architectural fabrics, with reference to the CEN/TC 250 European Code of Practice

- stronger justification for using the concept of the soap-film analogy in form-finding of fabric membranes, based on the results of the latest research and recommendations of the European Design Guide for Tensile Surface Structures

- derivation of a new 'shape' equation for the case of an elastic (extensible) suspension bridge cable under the deck weight and cable weight - it is shown how this equation reduces to an equation describing a catenary form (in the case of cable weight only) and a parabolic form (in the case of deck weight only) 
- a brand new section on the relevance of the shape equation for inextensible cables to the form-finding of rigid structural forms, such as arches. The focus here is on the inverted shape of a constant stress cable and how it relates to the design of the iconic Gateway Arch in St Louis, MO, USA

- a comprehensive and insightful coverage of patterning methods for fabric structures (i.e. $3 \mathrm{D}$ to $2 \mathrm{D}$ transformations required to manufacture the fabric membrane), presenting the latest non-standard computational approaches.

The aim of the book is to enhance understanding of tension structures from both practical and theoretical points of view and to provide insights into problems associated with the computational modelling of their structural form and behaviour. 
Acknowledgements I wish to thank James R Smith for his support, encouragement, and stimulating discussions during the research and preparation of the book.

I felt privileged to be working with the development editor Inês Pinheiro (ICE Publishing) on the preparation of this book. Her practical help and an incredible amount of enthusiasm contributed to improvements in the quality of exposition, and completion of the manuscript on time.

I am grateful to Juergen Bradatsch and Julia Stumpf at SL Rasch Gmbh, and also Stefania Lombardi at Canobbio Textile Engineering $\mathrm{Srl}$ for providing technical information on their fabric structures' projects, which feature in the book.

I wish to thank Malcolm Millais, whose constructive critique of the first edition of the book brought a number of improvements to the second edition.

I also wish to acknowledge the use of some of the illustrations provided by my former researchers: P. D. Gosling (Figures 7.7, 7.13, 7.14), T. S Lewis (Figures 7.15, 7.16, 7.19-7.24), and J. S. Brew (Figures 7.8-7.12, 7.20). 
Downloaded by [] on [26/04/23]. Copyright (C ICE Publishing, all rights reserved. 


\section{About the author}

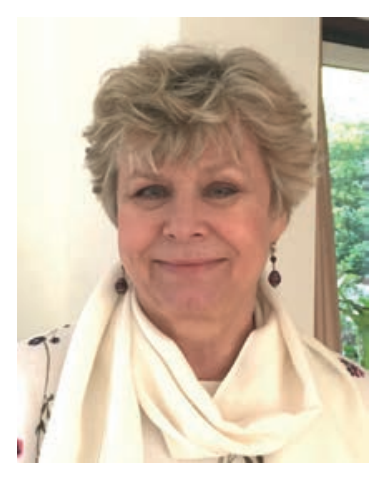

Wanda Lewis is an Emeritus Professor at the School of Engineering, University of Warwick. She is a chartered engineer and a Fellow of the Institution of Civil Engineers. During her 30-year research into tension structures she has developed an interest in optimal structural forms arising from a process of form-finding - a process of shaping an object by applying, or controlling, forces on it. In this regard, it is a process analogous to that observed in nature. As shown by the practical projects featured in the book, form-finding based on natural design principles leads to outstanding designs, such as the minimal umbrella structures in Madinah, Saudi Arabia. The author has led a number of European and national research projects, including Designing for the 21 st Century, carried out in collaboration with the Courtauld Institute of Art, London (http://www2. warwick.ac.uk/fac/sci/eng/design21/). 